\title{
Effects of compost particle size, moisture content and binding agents on co-compost pellet properties
}

\author{
Lakshika Hettiarachchi ${ }^{1,3^{*}}$, Nilanthi J ayathilake ${ }^{2}$, Sudarshana Fernando ${ }^{2}$, Sanja Gunawardena ${ }^{1}$ \\ (1. Department of Chemical and Process Engineering, Faculty of Engineering, University of Moratuwa, Sri Lanka; \\ 2. International Water Management Institute, P.O. Box 2075, Colombo, Sri Lanka; \\ 3. Sri Lanka Council for Agricultural Research Policy, No.114/9, Wijerama Mawatha, Colombo 07, Sri Lanka)
}

\begin{abstract}
Composting is one of the sustainable answers for the management of organic municipal waste. Bulky nature of loose compost is one of the main drawbacks in promoting compost in agriculture and pelletization of compost can offset these drawbacks. In this study, the optimum conditions in a die and roller pelletizer to form pellets with desirable properties; bulk density, compressive strength, pellet length and disintegration ability with compost particles of different mesh sizes $(2.5,3.5$, $5 \mathrm{~mm})$, moisture contents $(25 \%, 30 \%, 35 \%, 40 \%, 45 \%)$, different amounts and types of binding agents $(1 \%, 2 \%, 3 \%$ by weight of Rice Flour (RF), Lime, Rock Phosphate (RP)) were investigated. Pelletizing increased the bulk density of compost. Compost with $\leq 5 \mathrm{~mm}$ particles and $25 \%$ moisture content resulted pellets with the highest compressive strength and a higher percentage of long pellets. However, the tested properties varied with the type and the amount binding agents used with compost. Disintegration was not observed in pellets free of binding agents during the tested period but binding agents enhanced disintegration. Both machine efficiency and production efficiency decreased with increased moisture in compost and increased with increased compost particle size. However, increased amounts of binding agents in compost reduced the machine efficiency. This work shows that compost pelletizing with and without binding agents, enhanced properties of compost required in transportation, storage and application in agriculture.
\end{abstract}

Keywords: binding agents, co-compost, moisture content, particle size, pellets compressive strength DOI: $10.25165 /$ j.ijabe.20191204.4354

Citation: Hettiarachchi L, Jayathillake N, Fernando S, Gunawardena S. Effects of compost particle size, moisture content and binding agents on co-compost pellet properties. Int J Agric \& Biol Eng, 2019; 12(4): 184-191.

\section{Introduction}

Composting is a favourable solution for the disposal of organic waste in urban waste management. It is an aerobic process that helps to reduce the volume of waste, kill pathogens that may be present in waste and more importantly reduces leachate generation in decomposition. Compost contains decomposed plants and animal manure with various types and quantities of nutrients that are required for plant growth and hence has a great potential in crop production.

Although composting of organic fraction in Municipal Solid Waste (MSW) is considered as a win-win solution, municipal scale compost projects rarely sustain in low-income countries due to low demand for compost. This leads to projects failure in medium and long-term situations as a result of cost recovery and unsustainable cash flow problems.

Previous studies disclosed one major reason for low demand for compost by farmers as its bulky nature (i.e. low bulk

Received date: $2018-04-26 \quad$ Accepted date: $2019-04-18$

Biographies: Nilanthi Jayathilake, Master, research interest: Waste Management, Resource Recovery and Reuse, Circular Economy, Email: N.Jayathilake@cgiar.org; Sudarshana Fernando, PhD, research interest: City Region Food System, Waste Management, Resource Recovery and Reuse, Email: S.C.Fernando@cgiar.org; Sanja Gunawardena, $\mathrm{PhD}$, research interest: Biological systems for wastes and wastewater treatment, Bio-refinery for energy and chemicals, Email: sanjag@uom.lk.

*Corresponding author: Lakshika Hettiarachchi, Master, research interest: Water Management, Organic Agriculture, Waste Management, University of Moratuwa, Sri Lanka / Sri Lanka Council for Agricultural Research Policy. Tel: +94112689939, Fax: +94112682951, Email: Lakshikagihan02@gmail.com. density $)^{[1,2]}$. Moreover, loose compost hinders value proposition due to large space requirement for storage and transportation, which escalates the product price. In addition, at farm level, application of compost needs high labour involvement and there can be health concerns owing to dusty nature of compost ${ }^{[3-5]}$.

Pelletization (densification) using mechanical forces can provide a practical solution to increase the density. Animal feed and energy pellet production have been done for long and has extensively been studied ${ }^{[3,6-10]}$ but rarely for compost. Pelletizing of compost is an immerging area that needs in-depth understanding. Researchers have shown that pelletizing can be accomplished successfully for composted faecal sludge (FS) and FS: saw dust co-compost ${ }^{[11]}$. However, studies on physical properties of compost pellets made out of sorted MSW comprised with market waste as the major component have not yet been carried out.

During pelletizing, compost is compressed in to high-density, cylindrical shaped pellets. Pelleted compost can counter balance the most draw-backs associated with loose compost and beyond. It facilitates economical long distance transportation and low cost storing. Pellets with uniform length and diameter can be placed precisely under the soil surface next to the seed for more immediate effect and enable mechanical fertilization using seeding equipment. Further, compost pellets produce low levels of dust compared to loose compost and hence handling of pellets is convenient at farm level. In addition, densified animal feed and FS do not deteriorate during prolonged storage, preserves nutrient quality, and gradually release nutrients with time due to slow disintegration ${ }^{[3,6,11-15]}$.

Studies on conventional processes for pressure-assisted densification have been carried out and classified into three types: extruding, pelleting, and briquetting/cubing ${ }^{[15]}$. In an extruder, 
raw material is compressed by a screw through a die to form cylindrical shaped compressed particles. In pelleting, the feed material is pressed through open-ended dies to form pellets. As reported in literature, there are two main kinds of pelletizing machines available in the market; disk pelletizer mainly used for dry molding and extruder type pelletizer used for wet molding ${ }^{[3]}$.

Densification increased density of various biomass including agricultural residues and irradiated dewatered fecal sludge ${ }^{[1,15,16]}$ and density increase was around $20 \%-50 \%$ for FS based compost pellets when compared to loose product ${ }^{[11]}$. However, forming biomass into pellets depends on physical properties of the ground particles and the process variables during pelletizing ${ }^{[4]}$. This indicates particle size of the input material could be a key parameter governing pellet properties. Process variables can be moisture content, particle size of raw material (biomass), particle stiffness, binding agents and the pelletizing technology ${ }^{[7,13,16,17]}$. Further, required moisture content for pelletizing depends on the input material, binder material type, and binder concentration ${ }^{[11]}$.

Organic and inorganic binders have been employed for densification of biomass ${ }^{[15]}$. Chemical binders such as lignosulfonate, lime and biological binders such as molasses, starch, waste paper, and sawdust would positively affect the quality of the densified products ${ }^{[13,15]}$. Water is also a suitable binding aid in briquetting mixtures containing water-soluble constituents such as starches, sugars, soda ash, phosphate salts, and calcium chloride ${ }^{[18]}$.

Binding agents in the range of $0.5 \%$ to $5 \%$ (by weight) in the feed have increased the quality standards or marketing requirements of an agricultural residue of Alfalfa pellets minimizing the pellet quality variations ${ }^{[13]}$. In biomass pelletizing including woody biomass, binders or stabilizing agents have been used to reduce the pellet springiness and to increase the pellet density and durability ${ }^{[18,19]}$.

It is reported that hydrated lime (calcium hydroxide) and pea starch as suitable binders for the production of durable and hard Alfalfa pellets ${ }^{[13]}$. Studies have been done on the effects of cassava starch and clay as binders for pelletization of FS: Saw dust co-compost and reported that pretreated binders either through gamma irradiation or pre-gelatinization improved the binding ability ${ }^{[11]}$.

For a given pelletizer, the compressive force and the pelleting method are established. Hence, parameters that can be altered to affect pellet strength and size (length) are particle size, moisture content and the type and amount of binding agent. Therefore, main objectives of this study were to investigate the effect of particle size and the moisture content of compost on densification and strength of compost pellets that can be used and transported without enduring problems associated with loose compost and to identify viable binding agents to produce compost pellets with desirable length, strength, bulk density and disintegration ability.

\section{Materials and method}

Co-compost used in pelletization work was produced using MSW and dried FS (DFS) at 9:1 weight ratio and the characteristic of compost used is given in Table $1^{[20]}$.

Commonly employed die and roller method was used to produce compost pellets and the pelletization machine (Figure 1) has the following specifications; input voltage $415 \mathrm{~V}, 30 \mathrm{HP}$ motor, a die consisting of $6 \mathrm{~mm}$ diameter holes.

The improved pelletization process adopted in this work is shown as a block diagram in Figure 2. Firstly, co-compost was sieved to get favorable sized particles using three different mesh sizes; $2.5 \mathrm{~mm}, 3.5 \mathrm{~mm}$ and $5 \mathrm{~mm}$ sieves. The maximum particle size of locally marketable compost is $5 \mathrm{~mm}$ and hence these values were selected to meet the local standard.

Table 1 Characteristics of compost used in palletization

\begin{tabular}{|c|c|}
\hline Parameter & Value \\
\hline $\mathrm{C} / \mathrm{N}$ ratio & 6 \\
\hline Total nitrogen $(\mathrm{N}) / \mathrm{mass} \%$ & 1.4 \\
\hline Total phosphorous (P)/mass \% & 1.5 \\
\hline Water soluble phosphorous /mass \% & 0.44 \\
\hline $\mathrm{EC} / \mu \mathrm{S} \cdot \mathrm{cm}^{-1}$ & 4300 \\
\hline $\mathrm{pH}$ & 7.6 \\
\hline $\mathrm{Cr} / \mathrm{mg} \cdot \mathrm{kg}^{-1}$ & 58 \\
\hline $\mathrm{Cu} / \mathrm{mg} \cdot \mathrm{kg}^{-1}$ & 46.3 \\
\hline $\mathrm{Cd} / \mathrm{mg} \cdot \mathrm{kg}^{-1}$ & 0.5 \\
\hline Fecal coliform/MPN $\cdot g^{-1}$ & 13.3 \\
\hline Total coliform/MPN $\cdot \mathrm{g}^{-1}$ & 24 \\
\hline
\end{tabular}

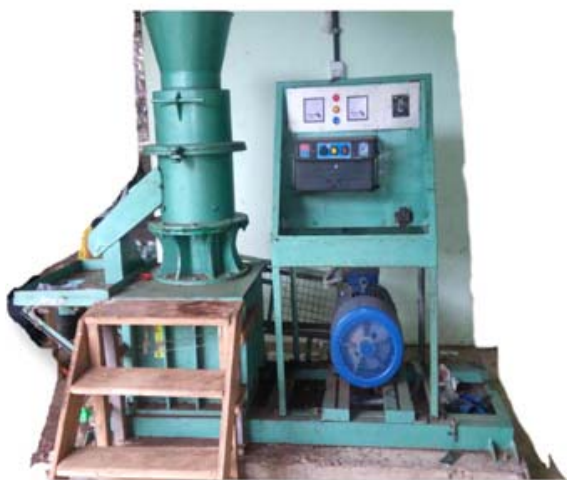

Figure 1 Die and roller machine used in co-compost pelletization

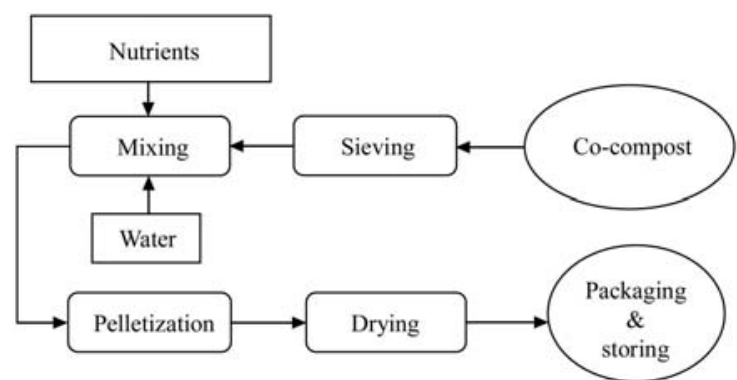

Figure 2 Schematic block diagram of improved pelletization process used for pelletization of co-compost

After sieving the oversized particles remained on the sieve were discarded. So that three particle sizes $(\leq 2.5 \mathrm{~mm}$ (particle category $1-\mathrm{PC} 1) ; \leq 3.5 \mathrm{~mm}$ (PC2) and $\leq 5 \mathrm{~mm}$ (PC3)) were used in pelletization work. Then, water was added to sieved compost to adjust the moisture to the required level (25\%-45\% with $5 \%$ increments) before the mixture was fed to the pelletizer. Finally, the produced pellets were sun dried, sorted and packed.

PC-3 compost with $25 \%$ moisture was used to prepare pellets with 3 different binding agents; rice flour (RF), lime (L) and Rock Phosphate (RP). All these binding agents are locally available and hence low cost. In addition, RF has the binding ability during pelletization and rapid disintegration ability at the field while RP is an inorganic fertilizer generally used in agriculture and this process gives value addition to a local raw material.

Effects of particle size, moisture content, and binding agents on length, strength, bulk density (packing density) and disintegration of co-compost pellets were investigated. The conditions used are summarized in Table 2. 
Table 2 Summary of material used, feed particle size and moisture level used in compost pelletization

\begin{tabular}{|c|c|c|c|}
\hline Material used & $\begin{array}{l}\text { Particle } \\
\text { Size/mm }\end{array}$ & $\begin{array}{c}\text { Moisture } \\
\quad / \%\end{array}$ & $\begin{array}{l}\text { Investigated } \\
\text { parameters }\end{array}$ \\
\hline FS:MSW co-compost & $\begin{array}{l}\leq 2.5 \\
\leq 3.5 \\
\leq 5.0\end{array}$ & 25 & $\begin{array}{l}\text { Pellet length } \\
\text { Compressive strength } \\
\text { Bulk density } \\
\text { Disintegration } \\
\text { Production Efficiency } \\
\text { Machine Efficiency }\end{array}$ \\
\hline FS:MSW co-compost & $\leq 5.0$ & $\begin{array}{l}25 \\
30 \\
35 \\
40 \\
45\end{array}$ & $\begin{array}{l}\text { Pellet length } \\
\text { Compressive strength } \\
\text { Bulk density } \\
\text { Disintegration } \\
\text { Production Efficiency } \\
\text { Machine Efficiency }\end{array}$ \\
\hline $\begin{array}{l}\text { FS:MSW co-compost with } \\
\text { binding agents }(1,2,3 \% \text { by } \\
\text { weight) } \\
\text { Rice Flour } \\
\text { Lime } \\
\text { Eppawala Rock Phospate }\end{array}$ & $\leq 5.0$ & 25 & $\begin{array}{l}\text { Pellet length } \\
\text { Compressive strength } \\
\text { Bulk density } \\
\text { Disintegration } \\
\text { Production Efficiency } \\
\text { Machine Efficiency }\end{array}$ \\
\hline
\end{tabular}

Initial moisture content of co-compost was measured using an analog portable moisture meter (Vktech-54433). In order to adjust moisture, the method adopted by the British Standards Institute $^{[21]}$ for moisture alteration in clay soils was used. According to the method a measured volume of water was added to compost, thoroughly mixed (manually), placed in a polythene bag to avoid moisture loss by evaporation and then allowed $24 \mathrm{~h}$ to settle. After that the moisture level was measured before feeding to the pelletizer. Bulk density (packing density) refers to the mass of pellets per unit volume and was determined by the method given in ASAE Standards S269.5 $5^{[22]}$.

Compressive resistance of compost pellets was determined by diametrical compression test ${ }^{[13]}$ in which, cylindrical pellets are placed horizontally between two plates, and then two equal and opposite forces were applied in the radial direction of the pellets. The force at crack the pellet is read as the maximum crushing load a pellet can withstand.

Compost from all 3-particle size categories (PC1-3) was subjected to sieve analysis to obtain the size distribution of particles within each particle size category. Particle size distribution in compost pellets was determined by wet sieve analysis $^{[23]}$.

To determine the pellet length distribution, random samples of $200 \mathrm{~g}$ were taken from each pellet sample was segregated according to lengths of pellets; $<5 \mathrm{~mm}, 5-10 \mathrm{~mm}, 10-15 \mathrm{~mm}, 15-$ $20 \mathrm{~mm}$, and $>20 \mathrm{~mm}$. Weight of pellets in each length category was recorded and calculated as the weight percentage of the full sample.

A representative pellet sample of $50 \mathrm{~g}$ from each experiment with different particle sizes, moisture contents, and binding agents were tested for disintegration in the presence of water. The pellets were placed in transparent cups filled with $200 \mathrm{~mL}$ distilled water and kept undisturbed for one month. In addition, pellets prepared with PC 3 with $25 \%$ moisture and RF as the binding agent were transported in gunny bags for $50 \mathrm{~km}$ distance in a lorry which is the common transporting method of fertilizer to study the effect of pellet breakage during transportation.

Machine efficiency was considered as the weight percentage of pellets produced in a unit time and the production efficiency of the machine was calculated as the weight percentage of marketable pellets produced from a given compost sample.

All the data reported here are average values of three experimental studies carried out in each category.

\section{Results and discussion}

Initial (received) moisture content of loose compost (bulk compost) was found to be $25 \%$ (at $75 \%$ relative humidity) and this value was taken as the lowest level of moisture that can be present in loose compost.

Particle size distribution in loose compost of 3 particle categories is shown in Figure 3. Compost of PC1 and PC2 has higher percentage of small $(<2 \mathrm{~mm})$ particles while PC3 sample shows a good distribution of compost particles of different sizes.

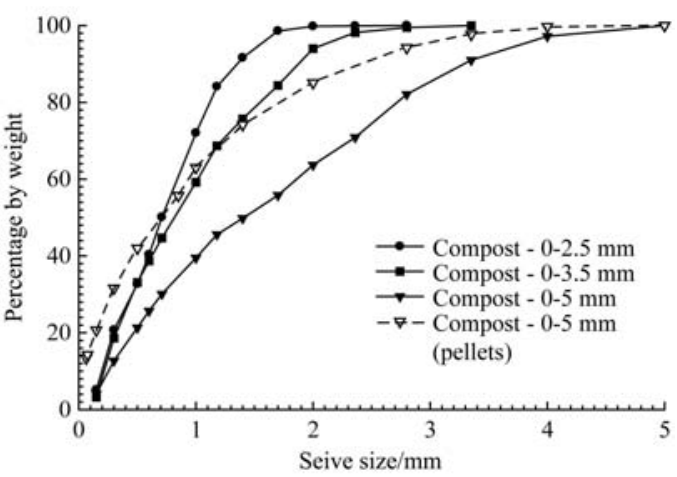

Figure 3 Particle size distribution of loose compost of all 3 particle size categories (PC 1, PC 2 and PC 3) and pellets of PC 3, moisture content $25 \%$

Figure 3 also shows the particle size distribution of compost pellets of PC 3 by wet sieve analysis. It can be seen that $73 \%$ (by weight) particles are smaller than $2.5 \mathrm{~mm}$ in PC3 loose compost while pellets from the same category has $92 \%$ (by weight) particles under $2.5 \mathrm{~mm}$ sieve size.

In this work compost pellets were made after sieving and moisture adjustment to compost but without grinding. As can be seen there is an upward shift in particle size distribution in compost pellets indicating that the percentage of smaller particles has increased during palletization; it was $26 \%$ increase for $2.5 \mathrm{~mm}$ size particles. This is a clear indication that even though grinding was not done prior to pelletizing, grinding of compost happened in the pelletizing machine during the process. Co-compost pellets made with PC1 is shown in Figure 4.

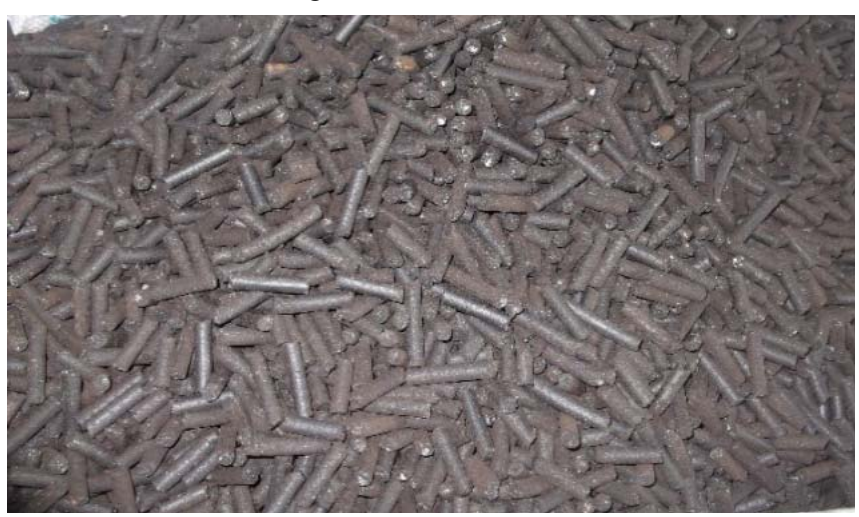

Figure 4 Compost Pellets made with co-compost (MSW+ FS) of

PC1 particles and 25\% moisture using die and roll pelletizer

\subsection{Effect of particle size}

\subsubsection{Pellet length distribution}

Length distribution (by weight) of compost pellets made with all three particle categories at 25\% moisture resulted higher percentage of 5-10 mm long pellets (Figure 5) and that was 35\%, $36 \%$ and $34 \%$ for pellets made with $\mathrm{PC} 1, \mathrm{PC} 2$ and $\mathrm{PC} 3$ 
respectively. Pellets made with PC1 have $32 \%$ (by weight) pellets shorter than $5 \mathrm{~mm}$ and it were only $22 \%$ and $21 \%$ respectively for pellets consisting of $\mathrm{PC} 2$ and $\mathrm{PC} 3$ particles.

The best particle size category to achieve long pellets with the selected die (6 mm in diameter) in this work is PC3 in which a wide variation of particle sizes is present. This wide range of particle sizes allows good compaction giving a good strength invariably resulting long pellets. Compost pellets with small particles; PC1 and PC2 resulted that more pellets that are shorter than $10 \mathrm{~mm}$ and this could be due to the easy movement of particles through the die without proper compaction giving rise to weaker pellets which are susceptible to break.

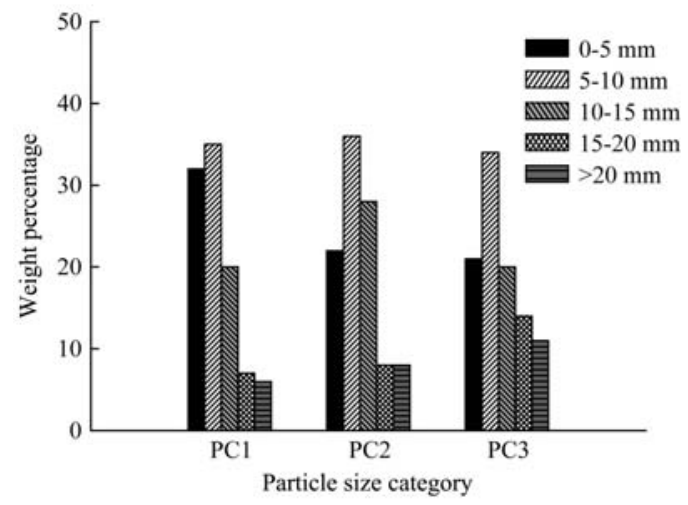

Figure 5 Weight percentage of pellets lengths of compost pellets prepared with $\mathrm{PC} 1, \mathrm{PC} 2$ and $\mathrm{PC} 3$ at $25 \%$ moisture

\subsubsection{Compressive strength}

From the plot of compressive strength (calculated as the load required to rupture $1 \mathrm{~cm}$ long pellet) with compost particle sizes (3 particle categories considered) (Figure 6) it can be clearly seen that pellet strength increases when the particle size is increased. Pellets made with PC1 could withstand only $43.0 \mathrm{~N} / \mathrm{cm}$ but pellets made with PC3 could withstand $64.3 \mathrm{~N} / \mathrm{cm}$.

As discussed in 3.1.1, a mixture of different particle sizes and a wide particle size distribution support compaction of material. Smaller particles fill gaps facilitating interlocking of particles and minimizing the voids present. In addition, short-range forces such as hydrogen bonds and Van der Waals forces are present in closely packed particles and these too contribute to increased pellet strength. Strong pellets do not break easily and hence they are comparatively long.

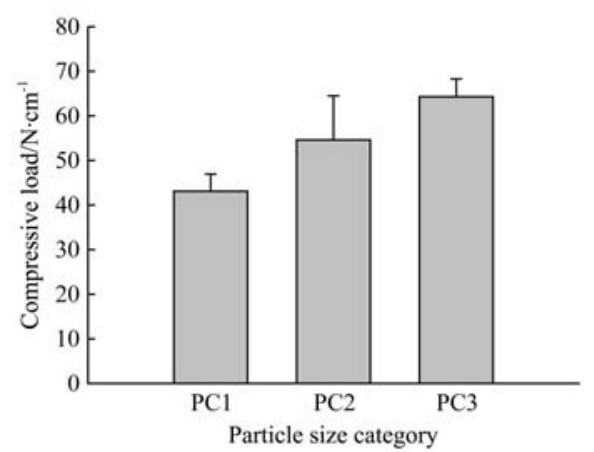

Figure 6 Variation of compressive strength of pellets prepared with $\mathrm{PC} 1, \mathrm{PC} 2$ and $\mathrm{PC} 3$ at $25 \%$ moisture with compost particle size

\subsubsection{Bulk density}

Bulk density gives an indication of the level to which compost (both loose and pellets) can be packed in a given volume and is highly important in compost transportation. According to Figure 7 , there is no much difference in the bulk density of loose compost, composed of different particles sizes and it was $557.0 \mathrm{~kg} / \mathrm{m}^{3}$, $551.0 \mathrm{~kg} / \mathrm{m}^{3}$ and $567.0 \mathrm{~kg} / \mathrm{m}^{3}$ for the 3 different particle categories; PC1, PC2 and PC3. However, bulk densities of compost pellets made with all 3 particle sizes have increased by $33 \%-45 \%$ due to compaction of compost in pellets increasing the total mass in a unit volume. Moreover, there is no distinct difference in bulk densities of compost pellets made from PC1 \& PC2 particles $\left(730.3 \mathrm{~kg} / \mathrm{m}^{3}\right.$ and $730.7 \mathrm{~kg} / \mathrm{m}^{3}$ ) and that may be due to similar distribution of pellet lengths in both categories. In both these categories, the presence of high percentage of short pellets allows better packing, filling the voids in the container.

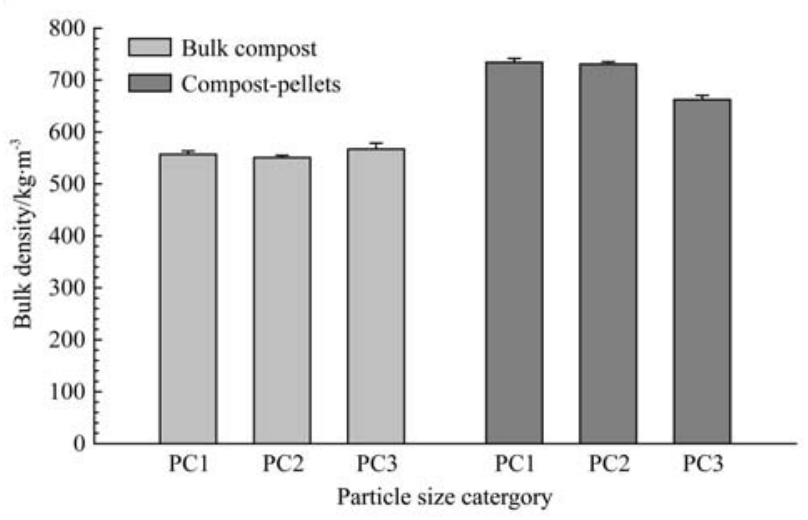

Figure 7 Bulk Density of loose compost and compost pellets made with $\mathrm{PC} 1, \mathrm{PC} 2$ and $\mathrm{PC} 3$ particles at $25 \%$ moisture

There is a drop in the bulk density of compost pellets made from PC3 $\left(687.5 \mathrm{~kg} / \mathrm{m}^{3}\right)$ in which a considerable amount of long pellets was present; when pellets are long packing is not good. Thus, this study demonstrates that in order to increase the bulk density, a mixture with appropriate amounts of both long and short length pellets are required.

\subsection{Effect of moisture content}

\subsubsection{Pellet length distribution}

Distribution of pellet length with moisture for PC3 is shown in Figure 8. For all moisture levels considered, the highest weight percentage was recorded for 5-10 mm length class and pellets longer than $20 \mathrm{~mm}$ showed the lowest percentage. Further, it can be seen that when the moisture content was increased, the percentage weight of long pellets decreased and that of short pellets increased.

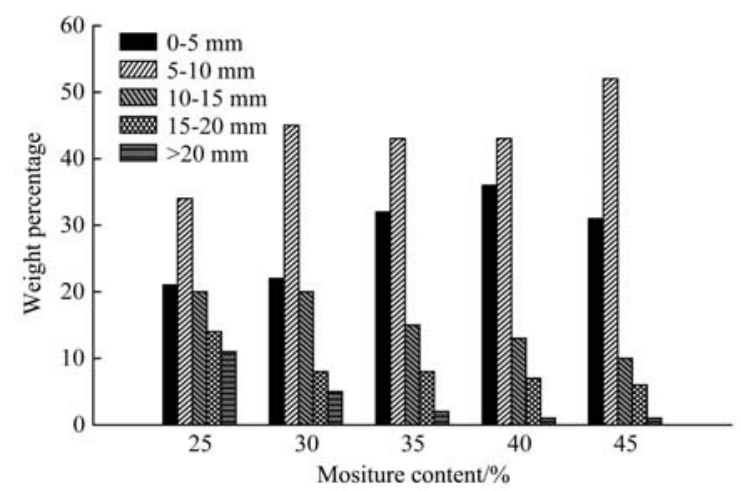

Figure 8 Weight percentage of compost pellets of different lengths at different moisture levels (pellets made out of PC3)

According to literature, moisture in the feedstock acts as an important factor in the pelletizing process. Moisture has an ability to serve as a binding agent as well as a lubricating agent and the right amount of moisture develops self-bonding properties in densification $^{[15]}$. However, with the increase of moisture, the distance between particles increases trapping water in voids 
creating a biphasic mixture (liquid phase and solid phase). In such a situation, intermolecular forces such as Hydrogen bonds and Van der Waals forces disappear weakening the forces between particles ${ }^{[4]}$ and hence strength of pellets decreases; resulting in short pellets as clearly seen in Figure 8. Weight percentage of 0$5 \mathrm{~mm}$ and $5-10 \mathrm{~mm}$ size long pellets increased from $55 \%$ at $25 \%$ moisture content to $83 \%$ at $45 \%$ moisture content. Therefore, higher the moisture level in compost, lower the strength of pellets and consequently shorter are the pellets. In addition, since lubricity and the fluidity of compost increases with moisture, compost easily pass through the die without proper compaction resulting short pellets. No previous studies have been carried out to determine the effect of moisture level on the strength and length of compost pellets and therefore this work provides valuable information on those aspects.

\subsubsection{Compressive strength}

Pellet strength of PC3 with increased moisture for five different moisture contents $(25 \%-45 \%$ in $5 \%$ increments) is shown in Figure 9. In all the samples tested, the highest strength was observed in pellets made with compost having $25 \%$, moisture and the compressive load was $64.3 \mathrm{~N} / \mathrm{cm}$ while the lowest strength resulted in pellets made with compost having the highest moisture content of $45 \%$ and the load required to break the pellets was $18 \mathrm{~N} / \mathrm{cm}$. As explained in 3.2.1, increased moisture in compost tends to produce weak pellets that rupture easily at low compressive strength.

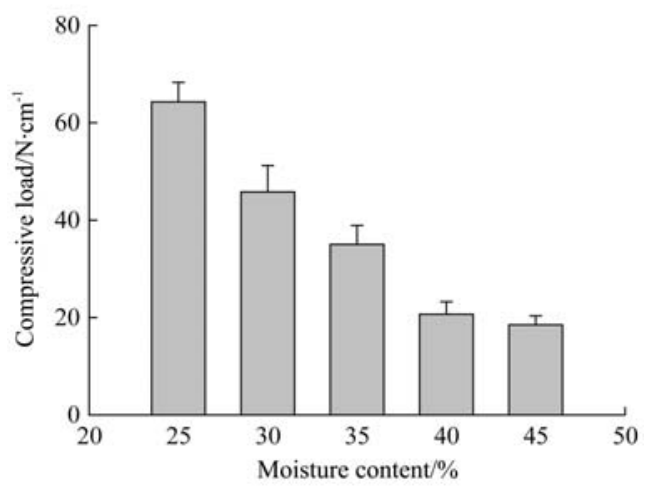

Figure 9 Variation of the compressive load of compost pellets of PC3 with moisture

When the moisture level is reduced, fluidity of compost falls increasing the frictional resistance as the compost passes through the holes of the die increasing the compaction which in turn increases the strength of compost pellets. The best moisture content to produce strong pellets is $25 \%$ for the Die and Roller disk pelletizer used in this work.

\subsubsection{Bulk density}

Figure 10 shows that bulk densities of pelleted compost of PC3 at various moisture contents. Bulk density of compost pellets increased when pellets were made with compost having increased moisture. This could be due to two reasons. One reason could be with the increase of moisture, pellets produced were short and hence those easily filled the container minimizing voids. The other reason could be due to increase in the mass of compost mixture with the addition of extra water and during pelletizing the extra moisture can be retained in the pellet.

\subsection{Production and machine efficiency}

The efficiency of production of marketable compost pellets from a given machine is an important factor that determines the commerciality of compost pellets. Effects of compost particle sizes and the moisture level on the production efficiency were evaluated and found that production efficiency increased with the increase of particle sizes considered in this work but decreased with moisture (Table 3). This can be explained with Figures 8 and 9; the pellet strength decreased with increased moisture resulting pellets that are weak and easy to break. So, the pellets become short and the saleability is low consequently reducing the production efficiency. Machine efficiency is the weight of marketable pellets produced in an hour and this is a property specific to the machine and the die used for a given compost sample. It was encountered that handling of moist compost was difficult in the pelletizer, there was clogging of the die reducing the machine efficiency. Reduction in production and machine efficiencies with high moisture levels have been reported for livestock manure compost ${ }^{[3]}$, cattle manure ${ }^{[4]}$ and swine manure ${ }^{[24]}$.

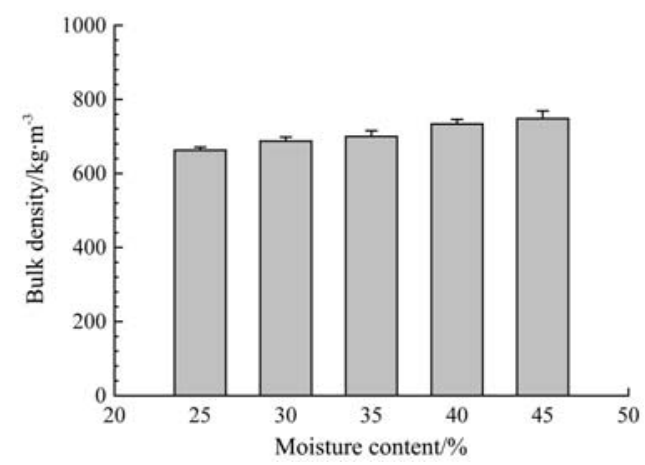

Figure 10 Variation of bulk density of compost pellets of PC3 with moisture

Table 3 Production and machine efficiency with varying particle size and moisture content for compost pelletizing

\begin{tabular}{cccc}
\hline \multicolumn{4}{c}{ Particle Size and Moisture Content } \\
\hline $\begin{array}{c}\text { Particle size } \\
/ \mathrm{mm}\end{array}$ & $\begin{array}{c}\text { Moisture content } \\
/ \%\end{array}$ & $\begin{array}{c}\text { Production } \\
\text { efficiency/\% }\end{array}$ & $\begin{array}{c}\text { Machine efficiency } \\
/ \text { Pellet kg } \mathrm{h}^{-1}\end{array}$ \\
\hline 2.5 & 25 & 55 & 30 \\
3.5 & 25 & 75 & 41 \\
5 & 25 & 85 & 64 \\
5 & 30 & 83 & 54 \\
5 & 35 & 78 & 50 \\
5 & 40 & 70 & 40 \\
5 & 45 & 64 & 25 \\
\hline
\end{tabular}

\subsection{Effect of binding agents}

\subsubsection{Pellet length distribution}

Length distribution (Percentage by weight) of compost pellets with 3 different binding agents (Rice flour - RF, lime and Rock phosphate - RP), 3 different weight percentages (1\%-3\%) and pellets without binding agents is shown in Figure 11. It is very clearly seen that the percentage of short pellets have decreased and that of long pellets have increased when binding agents (all 3 types) were used, compared to pellets with no binding agents. That is, all three binding agents used were able to enhance the binding ability of compost resulting long pellets.

Out of the three binding agents, the highest percentage of long pellets $(>20 \mathrm{~mm})$ was obtained when lime $(\mathrm{CaO})$ was used and the lowest percentage of long pellets was obtained when RF was used as the binding agents. The highest percentage of short $(<5 \mathrm{~mm})$ pellets resulted from RF added compost and the lowest percentage resulted from lime added compost.

According to Figure 11, lime is the most effective binding agent among all that resulted long pellets from compost having PC 3 particles and $25 \%$ moisture with the selected die $(6 \mathrm{~mm}$ in 
diameter) in pelletizing. In the presence of moisture, $\mathrm{CaO}$ forms $\mathrm{Ca}(\mathrm{OH})_{2}$ where $\mathrm{Ca}^{2+}$ and $\mathrm{OH}^{-}$ions are produced. $\mathrm{Ca}^{2+}$ is a strong ion and it tends to attract molecules present in the mixture to form ion dipole interaction, a type of Van der Walls force where interaction occurs between ions and a neutral molecules that help to bind particles together. The interaction can be strong; either charge of the ion increases or magnitude of the dipole of the polar molecule increases ${ }^{[25]}$. When the weight percentage of lime is increased, $\mathrm{Ca}^{2+}$ ions increases eventually resulting strongly bound particles to yield long pellets.

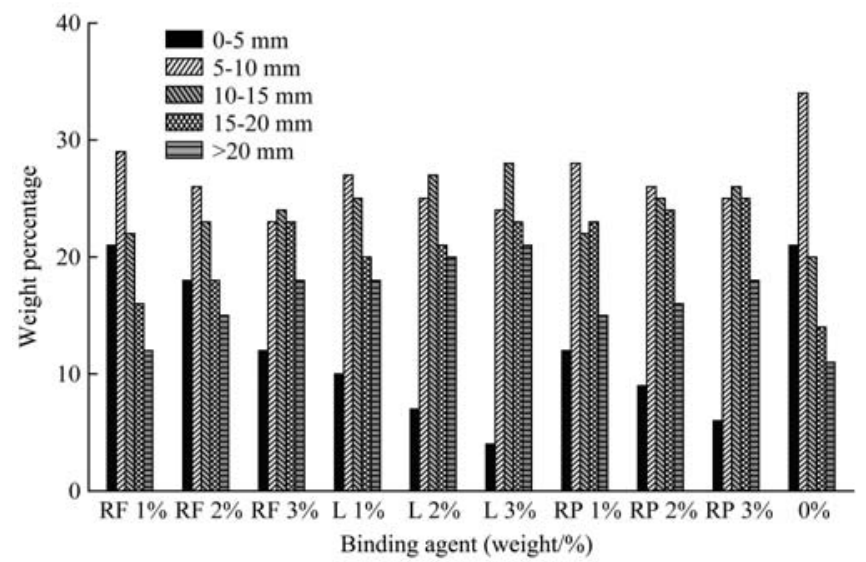

Figure 11 Pellet length distribution of compost of PC3 at 25\% moisture enriched with different types [RF- Rice Flour, L- Lime,

RP- Rock Phosphate] and weights of binding agents

RP is a less soluble binding material used in this experiment. The major element in RP is Ca which was present in the range of $21.5 \%-24.5 \%$ and the main constituent is apatite $\left(\mathrm{Ca}_{5}\left(\mathrm{PO}_{4}\right)_{3}\right.$ $(\mathrm{OH}, \mathrm{F}, \mathrm{Cl}))^{[26]}$. Although, $\mathrm{Ca}^{2+}$ ions are present in $\mathrm{RP}$, their interactions with compost are weaker than that of $\mathrm{Ca}^{2+}$ in lime because of the presence of $\mathrm{OH}^{-}, \mathrm{F}^{-}$and $\mathrm{Cl}^{-}$. These weak interactions give low strength to pellets and in turn produce short pellets.

RF has no effective free ions identified that help to produce strong pellet and this could be the reason for the production of more short pellets when RF was added to compost. Moreover, due to dry nature of RF, RF added compost ( $25 \%$ moisture), does move easily through the dies of the pelletizer to form short pellets. However, when RF percentage was increased there is a possibility of enhancing the interlocking and adhesion of particles due to pressure, which may result in sufficient strength in pellets as explained for biomass densification ${ }^{[13,14]}$.

However, RF is a potential binder at adequate moisture and heat ${ }^{[13]}$. Although RF in dry form has limited binding ability, gelatinized RF shows good binding ability due to stickiness and can make strong pellets ${ }^{[13,27]}$. Even if heat is generated during pelletization by friction, $30 \%-50 \%$ moisture level required ${ }^{[13]}$ for gelatinization is not available in compost.

\subsubsection{Compressive strength}

Figure 12 shows the change of compressive strength of compost pellets made with different types and weight percentages of binding agents. Pellets with no binding agents $(25 \%$ moisture and PC 3) have compressive strength of $64 \mathrm{~N} / \mathrm{cm}$ and when pellets with $1 \%$ by weight RF gave the highest compressive strength of $107 \mathrm{~N} / \mathrm{cm}$. However, when RF percentage was increased to $2 \%$ and $3 \%$, strength decreased to $70 \mathrm{~N} / \mathrm{cm}$ and $63 \mathrm{~N} / \mathrm{cm}$ respectively. With the increase of RF percentage, compost remained in dry form with reduced binding ability, which in turn resulted in weak pellets compared to other two binding agents.

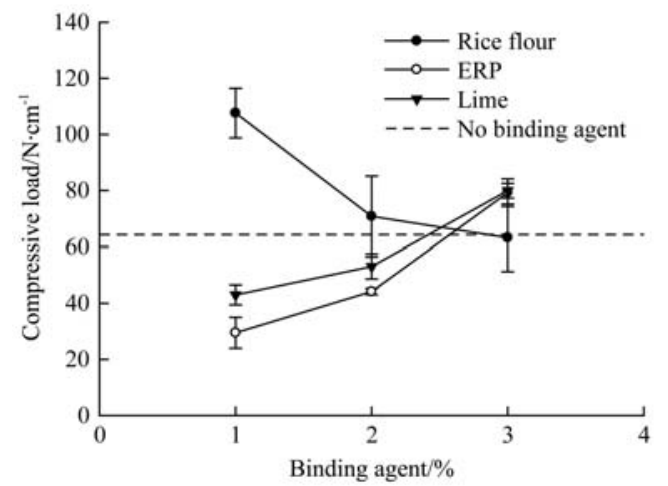

Figure 12 Variation of compressive strength with different binding agents and their weight percentage

Pellets with $1 \%$ (by weight) lime showed a decrease in compressive strength than that of pellets with no binding agents and then increased from $43 \mathrm{~N} / \mathrm{cm}$ to $80 \mathrm{~N} / \mathrm{cm}$ when the amount of lime increased from $1 \%$ to $3 \%$. RP added compost pellets also showed a compressive strength increase similar to lime added compost pellets from $30 \mathrm{~N} / \mathrm{cm}$ to $80 \mathrm{~N} / \mathrm{cm}$ when the binder weight percentage increased from $1 \%$ to $3 \%$.

Reason for the decrease in strength of $1 \%$ lime and $1 \%$ RP added pellets compared to pellets with no binding agent may be due to the moisture level. Water (moisture) in compost with no binding agent acts as a self - bonding agent and support higher densification by promoting Van der Walls forces, capillary pressure and interfacial forces for binding of particles ${ }^{[13,14]}$. With the addition of external binding agents, the ability of water to bind with compost gets limited resulting pellets with low strength. However, with the increase of lime to $2 \%$ and $3 \%$, compressive strength increased and this could be due to ion dipole interaction available in the compost mixture with strong $\mathrm{Ca}^{2+}$ ions in lime to form strong pellets as explained in 3.4.1.

Compressive strength of pellets having 1\% RP is less than that having $1 \%$ lime and may be due to weak interactions by the $\mathrm{Ca}^{2+}$ ions in RP with compost particles as explained in 3.4.1. However, gradual increase of RP increased the strength similar to that obtain with lime due to formation of solid bridges and Van der Walls forces at the temperature and pressure of densification ${ }^{[13,14]}$.

\subsubsection{Bulk density}

Bulk densities of compost with RF, compost pellets with RF and lime as binding agents at different weight percentages are shown in Figure 13. Bulk density of RF added compost increased from $400-300 \mathrm{~kg} / \mathrm{m}^{3}$ to $586-640 \mathrm{~kg} / \mathrm{m}^{3}$ after palletization while the bulk density of lime added compost pellets was $825-870 \mathrm{~kg} / \mathrm{m}^{3}$. Nevertheless, in all cases, with the increase binding agents from $1 \%$ to $3 \%$, there was a noticeable decrease in the bulk densities.

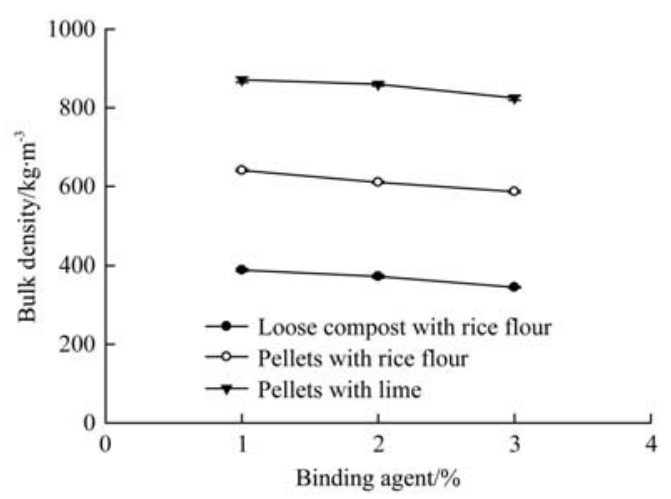

Figure 13 Variation of bulk density of compost with RF, compost pellets with RF and pellets with lime as binding agents 
RF added compost pellets resulted more short pellets and hence it is expected to increase the bulk density by minimizing the voids in the container used in the test. However, bulk density of pellets, made with lime added compost showed a noticeable increase than that of pellets made with RF added compost. Lime has $\mathrm{Ca}^{2+}$ that binds compost particles very strongly and results highly-densified product as previously mentioned in 3.4.1 and 3.4.2. Therefore, the weight of compost present in a unit length of a pellet is more in highly densified lime added pellets compared to RF added pellets, which are not densified as the former. Hence, that could be the reason for high bulk density in lime added pellets compared to RF added pellets.

\subsubsection{Production and machine efficiency}

As can be seen from Table 4, machine efficiency and the production efficiency varies with binding agents and their concentrations. With increasing concentration of binding agent from $1 \%$ to $3 \%$, the production efficiency increased but the machine efficiency gradually decreased.

Table 4 Production and machine efficiency of compost pelletizing with different binding agents and concentration for PC 3 and $25 \%$ moisture content

\begin{tabular}{cccc}
\hline Binding agent & $\begin{array}{c}\text { Concentration } \\
\text { /\% by weight }\end{array}$ & $\begin{array}{c}\text { Production } \\
\text { efficiency/\% }\end{array}$ & $\begin{array}{c}\text { Machine } \\
\text { efficiency } / \mathrm{kg}^{-1} \mathrm{~h}^{-1}\end{array}$ \\
\hline \multirow{3}{*}{ Lime } & 1 & 66 & 181 \\
& 2 & 67 & 170 \\
Rice-Flour & 3 & 68 & 130 \\
\hline \multirow{3}{*}{ Phosphate } & 1 & 57 & 120 \\
& 3 & 70 & 77 \\
& 1 & 85 & 74 \\
\hline
\end{tabular}

As can be seen from Figure 11, the percentage of marketable pellets longer than $10 \mathrm{~mm}$ in length has increased with the increased concentration of binding agents resulting increased production efficiency. However, the machine efficiency gradually decreased and this could be due to increase in density which slows down the movement of material through the die in a given unit time.

\subsection{Pellet disintegration}

Changes that happen in pellets can be due to interaction of $\mathrm{pH}$, temperature, movement of ions and diffusion of molecules ${ }^{[11]}$. As a result, molecules induce, swell, and then disintegrate. In addition, growth of microorganisms helps disintegration, especially in RF added compost where moisture and nutrients for microbial growth are available. When the percentage of RF in compost was increased, disintegration also increased from $60 \%$ to $90 \%$. RF added compost pellets are weak due to absence of ions to form intermolecular forces and these pellets disintegrate readily in the presence of water.

Percentage disintegration of pellets made with compost having different weight percentages of three binding agents is shown in Figure 14. Pellets made with no binding agents did not show any disintegration during the one-month testing period. However, incorporation of binding agents enhances pellet disintegration and pellets with RF showed the highest disintegration.

With the increase of the amount of RP, pellet disintegration decreased while lime added compost pellets did not show a change in percentage disintegration with increased amounts and remained around $10 \%$ during the one-month period considered for the experiment. Reason for low disintegration of pellets with RP could be low solubility of RP and hence it does not release ions and diffuse molecules for easy disintegration. Lime reacts with water to form $\mathrm{Ca}(\mathrm{OH})_{2}$ and then to $\mathrm{CaCO}_{3}$, which strongly binds compost particles together producing strong pellets (Figure 12). Solubility of $\mathrm{CaCO}_{3}$ is poor in water and therefore remains without disintegrating the pellet.

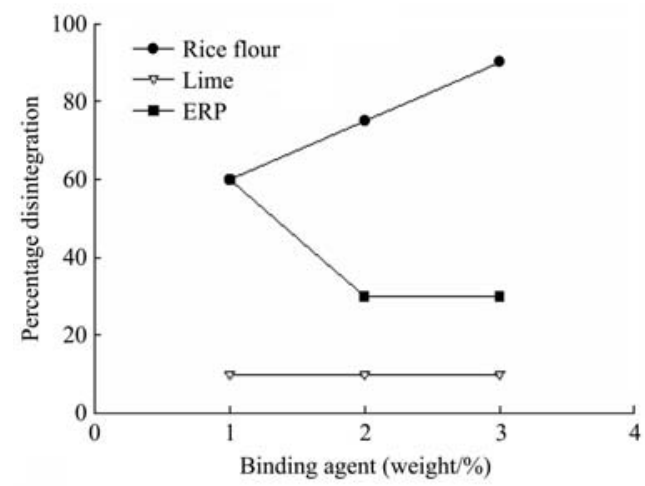

Figure 14 Percentage disintegration of compost pellets made with $1 \%-3 \%$ RF, lime and ERP as the binding agent

Pellets produced from PC3 compost particles with 25\% moisture content were transported a $50 \mathrm{~km}$ distance to observe the resistance against shocks and impacts. It was assumed that the compost would be marketed within maximum $50 \mathrm{~km}$ in urban context in Sri Lanka. Transport trial confirmed that the breakage of pellets were minimum even after $50 \mathrm{~km}$ transportation and pellets can endure shocks and impacts especially in packaging and transportation.

\section{Conclusions}

This study on co-compost pelletization was conducted using die and roller method which was proved to be less complex and economical compared to extruder method. Die and roller disk pelletizer has a grinding effect and hence additional step of grinding is not required giving advantages in commercialization.

Pelletization increased the bulk density of compost pellets due to compaction. Good compaction gives strength to pellets resulting long pellets. Compressive strength of pellets increased when compost particles have a wide range of size distribution (PC 3). However, it decreased with the increase of moisture because high moisture tends to block the dies of the pelletizer. Mixing of proper binding agents at correct weight percentages, increase compressive strength compared to pellets with no binding agents. With the increase of the binder RF, compressive strength gradually decreased but RP and lime gave promising increase of compressive strength with the increase of binder weight percentage.

Lime and RP as the binding agents in compost pelletizing significantly increased the percentage of long pellets compared to $\mathrm{RF}$ added pellets and compost with no binding agents.

Pellets made out of three different particle sizes (PC1, PC2 and PC3) and five different moisture contents (25\%-45\%) and with no binding agents showed $0 \%$ disintegration in water.

However, pellets with RP and Lime (PC3 and 25\% moisture) showed $10 \%$ disintegration when pellets with $\mathrm{RF}$ and same particles sizes and moisture showed $90 \%$ disintegration during the observation period of one month.

Among the three binding agents used in this experiment, lime and RP were found to be the most promising in terms of achieving strong and long pellets. However, disintegration of lime and RP added pellets is very much low and hence can be used for perennial 
agriculture enabling the pellets to degrade slowly and release nutrients gradually. Since, RF was very promising in disintegration, is more fitted for horticultural agriculture that lasts short terms and needs readily available nutrient to uptakes.

\section{Acknowledgements}

Authors wish to acknowledge International Water Management Institute, University of Moratuwa and the Supervisors of Solid Waste Management Unit of Municipal Council, Kurunegala, Sri Lanka for the unreserved support given to make this study a success. Further, this work was financially supported by the International Water Management Institute.

\section{[References]}

[1] Fernando S, Drechsel P, Amirova I, Jayathilake N, Semasinghe C. Solid waste and septage co-composting as a pathway to cost and resource recovery in Sri Lanka. 1st Specialist conference on municipal water management and sanitation in developing countries, Bangkok, Thailand, 2014.

[2] Rouse J. Rothenberger S, Zurbrügg C. Marketing compost: A guide for compost producers in low and middle-income countries. First edition. Dübendorf, Switzerland: Swiss Federal Institute of Aquatic Science and Technology (Eawag), 2008.

[3] Hara M. Fertilizer pellets made from composted livestock manure. FFTC Publication Database - Extension Bulletins, 2001. http://www.agnet.org/library.php?func=view\&style=type\&id=2011080115 4610. Accessed on [2018-03-02].

[4] Zafari A, Kianmehr M H. Effect of temperature, pressure and moisture content on durability of cattle manure pellet in open-end die mehtod. Journal of Agricultural Science, 2012; 4(5): 203-208.

[5] Obernberger I, Thek G. Physical characterisatio and chemical composition of densified biomass fuels with regard to their combustion behaviour. Biomass \& Bioenergy, 2004; 27: 653-669.

[6] Thomas M, van der Poel A F B. Physical quality of pelleted animal feed 1. Criteria for pellet quality. Animal feed science Technology, 1996; 89-112.

[7] Samson P, Duxbury R. Assessment of pelletized biofuels. 2000. http://www.susana.org/en/resources/library/details/702. Accessed on [2018-03-02].

[8] Roeper H, Khan S, Koerner I, Stegmann R. Low-Tech option for chicken manure treatment and application possibilites in Agriculture. Tenth International Waste Management and Landfill Symposium. Sardinia, Italy, 2005

[9] Suppadit T. Effect of pelleting process on fertilizing values of broiler litter. Journal ISSAAS, 2009; 15(2): 136-146.

[10] Babatope A, John J, Farouk F. Proximate composition and post-production stability of poultry waste fertilizer pellets. IJABR, 2012;
4(1\&2): $25-31$.

[11] Nikiema J, Cofie O, Impraim R, Adamtey N. Processing of fecal sludge to fertilizer pellets using a low-cost technology in Ghana. Environment and Pollution, 2013; 2(4): 70-87.

[12] Jaya S T, Lope T, Anthony O, Maria R M, Olaniya F. Effect of process variable on the quality characteristics of pelleted wheat distiller's dried grains with solubles. Biosystem Engineering, 2010; (105): 466-475.

[13] Tabil L G. Binding and pelleting charateristics of ALFALFA. University of Saskatchewan,Saskatoon, Saskatchewan,Canada. PhD thesis, 1996.

[14] Mishra P D, Grover S K. Biomass rriquetting: Technology and practices. Bakgkok, Thailand: FAO, 1999.

[15] Kaliyan N, Morey V. Factors affecting strength and durability of densified biomass products: Review. Biomass and Bioenergy, 2009; $1-87$.

[16] Mani S, Tabil, Sokhansanj S. Effect of compressive force, particle size and moisture content on mechanical properties of biomass pellets from grasses. Biomass and Bioenergy, 2006; 30: 648-654.

[17] Kamel G, Mohammad H K, Akbar A. Effect of moisture content and particle size on energy consumption for dairy cattle manure pellets. Agric Eng. Int. CIGR Journal, 2012;14 (3): 125-130.

[18] Mani S, Tabil L, Sokhansanj S. An overview of compaction of biomass grinds. Powder Handling and Processing, 2003;15(2): 1-9.

[19] Javon M C. North Carolina biomass availability and pellet production from mixed forest understory for bioenergy industry. Graduate Faculty of North Carolina State University, Raleigh, North Carolina, M.Sc. Thesis, 2010 .

[20] Jayawardena H M N, Fernando S C, Gunawardena S H P, Jayathilake N. Variations to key chemical parameters during dried feacal sludge and municipal solid waste co-composting. The Institution of Engineers, Sri Lanka, Annual Session of IESL, 2017; 537-543.

[21] BSI (BS standard). Methods of test for soils for civil engineering purposes - part 4: 1377-4, 1990.

[22] ASAE Standards. S269.5 Densified products for bulk handling definitions and method. American Society of Agricultural and Biological Engineers, 2012.

[23] Anon. How to carry out wet sieving. Retsch GmbH - Rheinische Strasse 36,42781 Haan, Germany, 2005.

[24] Romano E, Brambilla M, Bisaglia C, Pampuro N, Pedretti E F, Cavallo E. Pelletization of composted swine manure solid fraction with different organic co-formulates: effect of pellet physical properties on rotating spreader distribution patters. Int J Recycl Org Waste Agricult, 2014; 3: 101-111.

[25] Jordan C, Tim O. Ion-dipole interactions, 2017. https://brilliant.org/ wiki/ion-dipole-interactions/, Accessed on [2018-03-02].

[26] Ratnayake A R M S P, Navaratna A N. Spectroscopic determination of metal impurities in commercial raw material fertiliser of Sri Lanka. Ceylon Journal of Science (Physical Sciences), 2014; 18: 27-36.

[27] Nikiema J, Cofie O, Impraim R. Technology option for safe resource recovery from fecal sludge. Colombo, Sri Lanka: International Water Management Institute, 2014. 